\title{
Gas Chromatography and Flame Ionization Detection
}

National Cancer Institute

\section{Source}

National Cancer Institute. Gas Chromatography and Flame Ionization Detection. NCI

Thesaurus. Code C135454.

A method that combines a flame ionization detector with a gas chromatograph to identify and quantify organic species within a gas stream. 